\title{
Sciendo
}

Transport and Telecommunication, 2022, volume 23, no. 1, 102-112

Transport and Telecommunication Institute, Lomonosova 1, Riga, LV-1019, Latvia

DOI 10.2478/ttj-2022-0010

\section{AMMONIA AS CLEAN SHIPPING FUEL FOR THE BALTIC SEA REGION}

\author{
Laima Gerlitz, ${ }^{1}$ Eike Mildenstrey ${ }^{1}$, Gunnar Prause $^{2}$ \\ ${ }^{1}$ Hochschule Wismar, University of Applied Sciences: Technology, Business and Design \\ Philipp-Müller-Str. 14, 23966 Wismar, Germany \\ ${ }^{2}$ Department of Business Administration, Tallinn University of Technology \\ Ehitajate tee 5, 12616 Tallinn, Estonia \\ laima.gerlitz@hs-wismar.de \\ eikemildenstrey@yahoo.de \\ gunnar.prause@taltech.ee
}

The international shipping industry transports about 90 per cent of the global trade volume and is responsible for only two per cent of the anthropogenic carbon dioxide emissions. Consequently, the shipping sector is considered as an environmentally friendly transport mode. Nevertheless, global shipping can also improve its environmental footprint. So that in recent years clean shipping initiatives have been placed on the political agenda with the implementation of the Sulphur Emission Control Area (SECA) and Nitrogen Emission Control Area (ECA) regulations and the Global Cap. The next target of the International Maritime Organisation (IMO) in the sequel of the Paris Agreement of climate protection is dedicated to reduction of the Greenhouse Gas (GHG) emissions by up to $50 \%$ until the year 2050 .

The paper investigates and discusses the research questions to what extent ammonia can be used in Baltic Sea Region (BSR) to propel merchant vessels and how ammonia can fulfil future demands under technical, economic and infrastructural aspects to become the green fuel for the Baltic Sea Region (BSR) shipping industry. The study benchmarks the properties of ammonia as marine fuel against Marine Gas Oil (MGO) and Liquified Natural Gas (LNG). The research is based on secondary data analysis that is complemented by expert interviews and case studies, and the results are empirically validated by data that were collected during the EU projects "EnviSuM", "GoLNG", "CSHIPP" and "Connect2SmallPorts" that took place within the last four years in the BSR.

Keywords: Clean Shipping, Ammonia, Alternative Fuels, BSR, Decarbonisation

\section{Introduction}

Maritime shipping is an important backbone for global trade so that all kinds of regulations directly impact the economic frame conditions of the global economy. Currently, the IMO's focuses on environmental regulations on ship emissions, with the Sulphur Emission Control Area (SECA) regulations and the Global Cap implemented recently. Current and upcoming concerns are dedicated to the Nitrogen Emission Control Area (NECA) that was introduced in the Baltic and the North Seas in 2021, thus contributing to the decarbonisation of maritime transport. From several studies, it is well known that compliance with environmental regulations represents the most important economic challenges for shipowners due to the high impact of fuel costs on shipping economics and increased investment sums together with the long lifetime of ships with about 20 years (Prause \& Olaniyi, 2019; Seo et al., 2016; Sys et al., 2016). Thus, a wide choice of economically viable options for compliance have been discussed and tested in recent years, and all of these approaches have their pros and cons. In this light, shipowners constructed their compliance in the form of a weighted decision between capital expenditures and their resulting operational expenditure (Gu \& Wallace, 2017).

In the context of clean shipping, the BSR has enjoyed a leading role since in 2015; the first SECA in Europe was established in the North and Baltic Seas and offered thus a chance to gain experiences in low-sulphur shipping (Johansson \& Jalkanen, 2016). Hence, from the beginning of 2020 with the implementation of the Global Cap the BSR possesses the advantage of a five-year experience of all aspects of the SECA compliance compared to the rest of the maritime world. Unfortunately, only a few projects of the BSR that were concerning the shipping decarbonisation were realised. Yet, the accompanying research on the SECA impacts in the BSR spurred collecting and analysing economic and environmental data about shipping in the region. Johansson \& Jalkanen (2016) executed a maritime 
emission inventory based on over 1.65 billion AIS messages of about 8.000 IMO registered commercial ships in the BSR revealed the following results (Johansson \& Jalkanen, 2016, p. 1):

- The average number of daily plying ships on BSR:

- Total fuel consumption for shipping in BSR:

- Total emission of $\mathrm{CO}_{2}$ :

- Total other emissions:

ca. 1500 ships

ca. 5 million tons of $\mathrm{MGO}$

ca. 16 million tons $\mathrm{CO}_{2}$

$342 \mathrm{kt} \mathrm{NOx}, 23 \mathrm{kt} \mathrm{CO}_{2}$.

A 50 per cent cap of the GHG shall be reached by decarbonisation of maritime shipping. One promising strategy for shipowners and ship operators is here associated with a stable switch to alternative fuels, as it was proved to be successful in the case of transitional fuels, such as LNG. A promising candidate for fully-fledged clean shipping is ammonia as a carbon-free fuel that meets the aims of the IMO. Ammonia shows good advantages in handling and storage (Bilgili, 2021), and it ensures long sea voyages without any significant loss of cargo space for a reasonable price. Green ammonia, produced from e-hydrogen based on water electrolysis by renewable electricity, might become a major bunker fuel beyond 2030 (Vedachalam et al., 2022). In addition, ammonia may become a key accelerator of transition to the hydrogen economy (Erdemir \& Dincer, 2021; Wan et al., 2021). Yet, technology readiness for ammonia propelled vessels is still under construction and ammonia supply and value chains, including necessary infrastructure upgrade and real-world applications (Kurien \& Mittal, 2022, p. 3), thus enabling production, distribution, operation, and capitalisation is still underdeveloped. This bears a clear research gap (Ben Brahim et al., 2019, p. 1; Erisman et al., 2001, p. 1913). In addition, when it comes to ammonia, which is identified as one of the top three fuels for 2050, the majority of operationalisation challenges for ammonia are land-based, as the fuel is not available in the right locations at the right volumes (Haskell, 2021). There is a conflicting challenge of ensuring energy efficiency while securing production rate (MacFarlane et al., 2020).

However, building upon previous sound experiences in reducing negative environmental footprint through the SECA and NECA regulations in force and growing into a role model for clean shipping, the BSR has the best legal, economic, infrastructural and technological preconditions to become a testing ground for ammonia as a clean marine fuel and technology leading towards sustainable green growth. In contrast to the existing literature on ammonia, this research calls for an assessment of ammonia as clean shipping fuel from an ecosystem perspective, comparing it with other (multiple) fuel options and considering technical and economic feasibility, safety and environmental performance (Andersson et al., 2020, p. 1; Hansson et al., 2020, p.1; Korberg et al., 2021, p. 2).

In this light, the paper investigates and discusses the research questions to what extent ammonia can be used in the BSR for propelling merchant vessels and how ammonia can fulfil future demands under technical, legal, economic and infrastructural aspects to become a green fuel for the BSR shipping industry from a holistic perspective. The study benchmarks the properties of ammonia as marine fuel against MGO and LNG and positions it in the frame of applicable business models for affected BSR stakeholders. The research is based on primary data analysis - expert interviews and multiple cases deployed from the applied research projects across the BSR - EU projects "EnviSuM", "CSHIPP", "GoLNG" and "Connect2SmallPorts" that were or are being still implemented within the last four years in the BSR. In addition, the research is complemented by secondary data, in particular regarding fuel options' comparison.

The research provides both managerial and theoretical implications by revealing the next steps of ammonia integration within maritime operations from a systemic point of view, pinpointing the most sensitive framework conditions that need to be fulfilled within the regional ecosystem to prepare and enable ammonia operationalisation. Theoretically, the research links up the previous sound research discourses on alternative fuels' implications with the recent discourse on ammonia and hydrogen, reducing the addressed research gaps. It provides an integrative theoretical perspective on how path learning experiences can pave the way for sustainable and learning-based clean shipping by utilising proven practices to implement transitional alternative fuels, like LNG. Managers can benefit from this research by familiarising themselves with potential ammonia application models and forecasting their future fuel shift plans.

\section{Ammonia as a transitional fuel for transportation}

The NECA regulations from 2021 aimed at reducing NOx emissions, but they only apply to newly built ships, i.e. a significant reduction in maritime NOx emissions will be seen in future decades. The 
reduction of GHG and especially $\mathrm{CO}_{2}$ emissions by 50 per cent until the year 2050 represents another strategic direction of IMO. Currently, the increasing use of LNG in shipping can be considered as the first step towards decarbonisation. However, since LNG is composed of methane gas, this technology can only be a feasible solution for a transition period until decarbonised fuels are available. LNG is not able to decrease the global working potential by more than 8-20 per cent due to methane slip from the gas engine (Bengtsson et al., 2011, p. 97). Or when innovative low and zero-carbon solutions, such as biodiesel, Liquefied Bio Gas (LBG) and similar fuels come to the market (Bach et al., 2021; p. 1). In addition, longterm and deeper decarbonisation will require substantial financial incentives and the use of multiple different options (Balcombe et al., 2019; p. 72). Mostly discussed in this context are electricity, hydrogen and ammonia as marine fuels (Ampah et al., 2021; Xing et al., 2020; Zis \& Cullinane, 2020). In addition, similarly, as with the SECA, the NECA case is referred to as weak command-and-control regulation, including uncertainty pertaining to the dovetailing of existing and upcoming environmental requirements. Yet, the NECA development shows also higher endeavours to adopt transitional and more radical environmental innovations, which is particularly true for the BSR (Stalmokaite \& Yliskylä-Peuralahti, 2019, p. 14).

In this light, the present research aims at enhancing alternative fuels' utilisation by focusing on the options of ammonia as a clean shipping fuel in the BSR, which still misses practical implementation on the one hand. Still it appears to bear higher innovation potential, on the other hand, thus fostering its uptake and transition towards more sustainable regional development. Ammonia $\left(\mathrm{NH}_{3}\right)$, as a marine fuel, has no long history be it gained speed in recent years and in March 2021, a group of maritime industry players, including Maersk shipping company from Denmark, formed an alliance to develop a "comprehensive and competitive" supply chain for the provision of green ammonia. Currently, ammonia only appears as liquid cargo in maritime business, and only about 120 ports worldwide are equipped with ammonia trading facilities and six of them are located in the BSR (DNV-GL, 2020; Topsoe, 2020). The most important $\mathrm{NH}_{3}$ terminals are at the moment in Sillamäe (EE), Ventspils (LV) and Police (PL), but all of them are not used as marine fuel bunkering terminals.

Ammonia can be deployed as a single fuel or in combination with other fuels, such as diesel (Reiter \& Kong, 2008), hydrogen (Valera-Medina et al., 2017) or methanol (Rehbein et al., 2019). Ammonia power systems can achieve a system efficiency of more than $44 \%$ once used with a direct internal combustion engine (Zamfirescu \& Dincer, 2008). Similarly, ammonia can serve for hydrogen production (Giddey et al., 2017), storage and transportation (Xing et al., 2020) or be deployed in fuel cells (Cheliotis et al., 2021). Although ammonia is ranked beyond hydrogen for its positive environmental potential, its strength and advantages relate to physical, economic, technological and social aspects. It is because ammonia includes higher volumetric energy density, results in lower cost per unit of stored energy, is easier in handling and distribution if the infrastructure is established (Klerke et al., 2008, p. 2305).

A closer look at the characteristics and potentials of $\mathrm{NH}_{3}$ as marine fuel reveals that the conventional ammonia energy costs are comparable to energy costs of Very Low Sulphur Fuel Oil (VLSFO) and that the use of ammonia is the most economic carbon-free fuel (Kim et al., 2020). In addition, the handling of ammonia is well known from industrial processes; therefore, safe usage of $\mathrm{NH}_{3}$ on ships can be assumed. Global availability of ammonia is safeguarded, and marine dual-fuel engines for the use of VLSFO and $\mathrm{NH}_{3}$ already exist. So that maximal flexibility with minimal fuel costs is a realistic future option (Mildenstrey, 2021). Supplementary $\mathrm{NH}_{3}$ enjoys in liquid form comparable physical characteristics concerning temperature, pressure volume and weight for storage and transport like LNG. The existing LNG technologies can be used for $\mathrm{NH}_{3}$ logistics to a large extent. Indeed, if the current propulsion technology in the maritime sector continues to dominate, ammonia is one of the alternative fuels contributing to-wards decarbonisation (Prussi et al., 2021, p. 2)

In this light, ammonia deployment seems feasible, particularly in such markets as inland, coastal and short sea shipping (Xing et al., 2020, p. 13). As a result, its application and further development in the BSR appear to be feasible in environmental, economic, regulative, safety and technological aspects, as it is a forerunner in environmental responsibility and sustainability-driven growth and regional growth development (Ahlgren, 2019; Beyersdorff \& Lanthen, 2018; Böhme et al., 2016). Yet, it is worth mentioning that from the life cycle perspective, in the future, ammonia can be regarded as an alternative fuel if its production is based, e.g. on renewable energy sources used for green hydrogen production. Then, the environmental impact of ammonia might decrease (Bilgili, 2021), and environmental benefits are enhanced (Al-Aboosi et al., 2021). In this regard, green ammonia might become a fuel of the future for transportation (Al-Douri et al., 2021 Al-Enazi et al., 2021; Carvalho et al., 2021; Lloyd's Register, 
2020), power generation (Sánchez, 2021) and agriculture (Palys et al., 2021). However, since our economy is dependent on transitional solutions and needs to act and react today, ammonia does appear as a socially and economically feasible solution with regards to costs and compatibility of fuels (Ben Brahim et al., 2019, p. 8; Valera-Medina et al., 2021, p. 6964).

Against this background, studying ammonia and it's all potential combinations, would it be first grey ammonia and then transitioning to pure green ammonia. It's an essential step for the region that claims to continue its sustainable development trajectory with specific and feasible clean shipping actions and strategies.

\section{Methodology}

This research is based on desktop research about ammonia as a marine fuel and complemented by expert interviews and case studies. The expert interviews mainly embraced open-ended questions, whereby a quarter of the questions represented closed-ended questions that were grounded on a five-point metric scale. The vessel case study is based on real operational data of an existing vessel used to assess fuel consumption patterns and related cost and revenue values.

The research was further complemented by observations, an extensive literature review, analysis and examination of respective theories and approaches, topic-related policy regulations and guidelines, representing a systematic research procedure for elaborating a process, action and/or interaction about a substantial subject. The results are empirically validated by data that were collected during the EU projects "EnviSuM", "CSHIPP", "GoLNG" and "Connect2SmallPorts" that took place within the last four years in the BSR.

The underlying empirical data stem from different sources, so we followed the methodology of triangulation by applying and combining several research methods in the study of the same phenomenon. The used qualitative and quantitative studies combine different theories, methods, and empirical data to resolve tentative weaknesses or intrinsic biases related to the research questions by following Altrichter's et al.,'s (Altrichter et al., 2008) principle of giving a more detailed and balanced picture of the situation.

The used prices for different fuels and commodities comprising $\mathrm{MGO}, \mathrm{LNG}$ and $\mathrm{NH}_{3}$ are taken from statistical averages over the last four years, and all used prices are calculated in US\$ The research benchmarks the properties and concepts of ammonia as marine fuel against MGO and LNG.

\section{Patterns of Fuel Consumption for Shipping, Costs and Scenarios}

The emission inventory of Johansson and Jalkanen (Johansson \& Jalkanen, 2016) in the BSR yielded a total annual fuel consumption for shipping in the BSR of about 5 million tons of MGO, which translates into 11.5 million tons of $\mathrm{NH}_{3}$ as energy equivalent. These 11.5 million tons of $\mathrm{NH}_{3}$ would be needed to fuel commercial vessels in the entire BSR by $100 \%$ with ammonia, which could only represent a long-term target since even the shipping industry expects an $\mathrm{NH}_{3}$ demand of marine fuel $30 \%$ by 2050 [27]. By assuming this $30 \%$ also for the BSR, one can expect an annual $\mathrm{NH}_{3}$ demand for shipping in the BSR of about 3.5 million tons representing only $2 \%$ of the current yearly ammonia production of the world that sums up to 180 million tons. This is especially true considering the following locations and infrastructural needs: the BSR has around 200 ports with commercial activities; ca. Fifty regularly scheduled ferry and passenger ports are distributed over all nine BSR countries.

The DNV database indicates currently only six ports with ammonia terminals: Sillamäe (EE), Uusikaupunki (FI), Kokkola (FI) Köping (SE), Police (PL), Rostock (DE) and additionally the closely situated ports of Brunsbüttel (DE) Stenungsund (SE) and Porsgrunn (NO). Comparable results and structures are available for LNG (Gerlitz et al., 2018), technology that started with a few ports having respective infrastructure. In addition, $\mathrm{NH}_{3}$ bunker barges can be a solution, like it was with the LNG introduction tracing back to 2015. Indeed, ammonia application in the BSR can benefit from existing studies on socio-economic aspects, like value creation (Olaniyi \& Prause, 2020) and energy contracting (Olaniyi \& Gerlitz, 2019).

Given a container ship with a cargo capacity of 4.500 twenty-foot equivalent units (TEU) and a size of approximately 75.000 tons deadweight (TWD), the main engine has a power of $36.000 \mathrm{KW}$, and the auxiliary generators have a power of $3.600 \mathrm{KW}$ per unit. In our case, we assume a voyage with different load conditions, which result in various fuel oil consumptions (FOC). Furthermore, the total energy is calculated by considering the lower heating value of MGO to have a comparable parameter for the other fuels. The scenario is available in Table 1. 
Table 1. Annual scenario for fuel consumption of a 4.500 TEU vessel

\begin{tabular}{|c|c|c|c|c|}
\hline \multicolumn{5}{|c|}{ Size: $75.000 \mathrm{DWT}$} \\
\hline \multicolumn{5}{|c|}{ Power (ME): $36.000 \mathrm{KW}$} \\
\hline \multicolumn{5}{|c|}{ Auxiliary Engine Power: $3.600 \mathrm{KW}^{*} 4$} \\
\hline Voyage & Days & FOC ME (MT) & FOC AE (MT) & Total energy (GJ) for MGO \\
\hline On-route & 5 & 90 & 8 & 20.923 \\
\hline On route & 200 & 75 & 8 & 708.820 \\
\hline On-route & 60 & 60 & 8 & 174.216 \\
\hline On route & 25 & 45 & 8 & 56.577 .50 \\
\hline Maneuver & 10 & 25 & 16 & 17.507 \\
\hline Port & 60 & 0 & 8 & 20.496 \\
\hline \multirow{2}{*}{\multicolumn{3}{|c|}{ Total }} & Energy (GJ) & $998.539,50$ \\
\hline & & & Mass (MT) & 23.385 \\
\hline
\end{tabular}

By taking account of the fact that the fuel mass will not be an effective way to compare the fuels, the total consumed energy is the factor, which is taken for further calculation. For each fuel, the consumed energy is divided by the Lower Heating Value (LHV) to define the mass of each fuel that is needed to propel the vessel for the same voyages. Table 2 . shows the results of this calculation.

Table 2. Fuel mass resulting in total annual fuel costs

\begin{tabular}{|l|l|l|l|}
\hline & Fuel (MT/a) & High Price (USD) & Low Price (USD) \\
\hline MGO & 23.385 & 17.538 .750 & 8.184 .750 \\
\hline LNG & 19.971 & 12.981 .014 & 7.988 .316 \\
\hline LPG & 21.707 & 23.878 .118 & 17.365 .904 \\
\hline Methanol & 49.927 & 29.956 .185 & 12.481 .744 \\
\hline Biodiesel & 24.963 & 41.189 .754 & 14.978 .093 \\
\hline Hydrogen & 8.321 & 20.802 .906 & 8.321 .163 \\
\hline Ammonia & 53.685 & 80.527 .379 & 32.210 .952 \\
\hline
\end{tabular}

Furthermore, inside Table 2, the fuel mass is multiplied by the fuel price for each fuel and each scenario resulting in respective annual fuel costs. To simplify the calculation, the fuel prices stayed at a steady price for the whole year, which is in practice not possible. By considering only the mass, ammonia shows the most cost-intensive fuel costs due to the fact that ammonia has a low LHV compared to the other fuels. However, the mass is not the defining factor alone. All fuels result in different volumes; e.g., hydrogen would need 12 times more space than MGO. To continue with this example, costs for an alternatively fuelled vessel connect with the other costs and the possible cargo capacity loss. To achieve this, our hypothetical vessel is for our comparison purpose calculated first with an MGO propulsion system to provide a baseline. Based on our scenario, 55 ports of call are estimated, and an average cargo operation of $1.500 \mathrm{TEU}$ with a freight rate of $1.000 \mathrm{USD}$ is estimated. This calculation leads to a gross annual revenue that is further subtracted by the vessels' cost. In our case, the annual operating, voyage, capital and periodic maintenance costs are calculated based on the estimation, that the voyage costs are 33 per cent, periodic maintenance 2 per cent, operating costs 18 per cent and the capital costs are 47 per cent of the annual costs of a five-year-old vessel. In the scenario, the voyage costs consist of the fuel costs and the charges for tugs, canal passage etc., are estimated at 3 million USD per annum. Based on this the other costs have been calculated respectively. The summary of the assumptions is shown in the Table 3.

Table 3. Cost scenario for 4.500 TEU MGO vessel

\begin{tabular}{l|l}
\hline Containership & Fuel Cost \\
\hline Fuel type & MGO \\
\hline Cargo capacity [TEU] & 4.500 \\
\hline Annual port of calls & 55 \\
\hline Average cargo operation [TEU] & 1.500 \\
\hline Freight rate [USD] & 1.000 \\
\hline Gross revenue per port [USD] & $1.500,000$ \\
\hline Annual gross revenue [USD] & $82.500,000$ \\
\hline Annual operating costs & $8.651,864$ \\
\hline Annual voyage costs & $12.861,750$ \\
\hline Annual interest & $22.590,977$ \\
\hline Annual periodic maintenance & 963.318 \\
\hline Cumulative annual costs & $48.065,909$ \\
\hline Annual net revenue before tax & $34.434,091$ \\
\hline
\end{tabular}

In the next sub-step, the fuels have been connected with their resulting fuel volume in their bunker tanks and the possible cargo space loss that occurs. In this example, each unit of nominalised volume from table 13 results in a cargo capacity loss of 250 TEU. The total cargo loss has been translated into per 
cent, and this share has been deducted from the annual revenue before taxes, which leads to different annual gross revenues for each fuel system, respectively.

Following this calculation, the final revenue is calculated for each fuel in Table 4. Afterwards, the annual fuel costs are calculated in high $(\mathrm{H})$ and low $(\mathrm{L})$ price scenarios, where each of them is summarised with their remaining costs from Table 3, which are estimated to stay steady.

Table 4. Annual revenue and costs for each scenario

\begin{tabular}{l|l|l|l}
\hline & Iost cargo capacity [TEU] & Iost cargo capacity [\%] & Annual revenue [USD] \\
\hline MGO & 0 & 0 & $82.500,000$ \\
\hline Methanol & 308 & 7 & $76.725,000$ \\
\hline Biodiesel & 13 & 0 & $82.500,000$ \\
\hline LNG & 175 & 4 & $79.200,000$ \\
\hline LPG & 395 & 9 & $75.075,000$ \\
\hline Hydrogen liquid & 795 & 18 & $67.650,000$ \\
\hline Hydrogen (350 bar) & 2.938 & 65 & $28.875,000$ \\
\hline Ammonia & 535 & 12 & $72.600,000$ \\
\hline
\end{tabular}

By evaluating this data, the net annual revenue before taxes will be calculated by subtracting each fuel cost scenario from the respective gross annual revenue. The results are shown below in Table 5.

Table 5. Revenue before taxes for each case

\begin{tabular}{l|l|l}
\hline & Net revenue high & Net revenue low \\
\hline MGO & $29.757,091$ & $39.111,091$ \\
\hline Methanol & $11.564,656$ & $29.039,097$ \\
\hline Biodiesel & $6.106,087$ & $32.317,748$ \\
\hline LNG & $31.014,827$ & $36.007,525$ \\
\hline LPG & $15.992,722$ & $22.504,937$ \\
\hline Hydrogen liquid & $11.642,935$ & $24.124,678$ \\
\hline Hydrogen (350 bar) & $-27.132,065$ & $-14.650,322$ \\
\hline Ammonia & $-5.552,095$ & $18.606,119$ \\
\hline
\end{tabular}

The results from Table 5 clearly show the high dependency of hydrogen and ammonia on their fuel price. If their fuel price will not be lower or subsidised or the other fuels will not get more stringent rules for further $\mathrm{CO}_{2}$ reductions, ammonia and hydrogen might be less competitive due to cargo capacity losses which lead to reduced revenue. Together with high fuel costs, this could be a major problem for these fuels. Furthermore, ammonia is needed in higher numbers due to its low LHV resulting in high total bunker cost per annum. LNG, LPG, Methanol and Biodiesel show good results for their bunker price in high and low-price scenarios. Furthermore, they show good potential due to their LHV in combination with cargo space loss leading to a respectively better net annual revenue.

The calculation has been done in a simplified version. Other parameters could as well influence this calculation though. For example, operating costs have been estimated to be the same in each scenario. Hydrogen would acquire more operating costs because of the higher energy consumption for cooling and compressing, which will finally lead to more cargo space loss due to the fact that more hydrogen will be needed to provide this energy. This might be a good advantage for ammonia, which needs less cooling than hydrogen to stay liquefied.

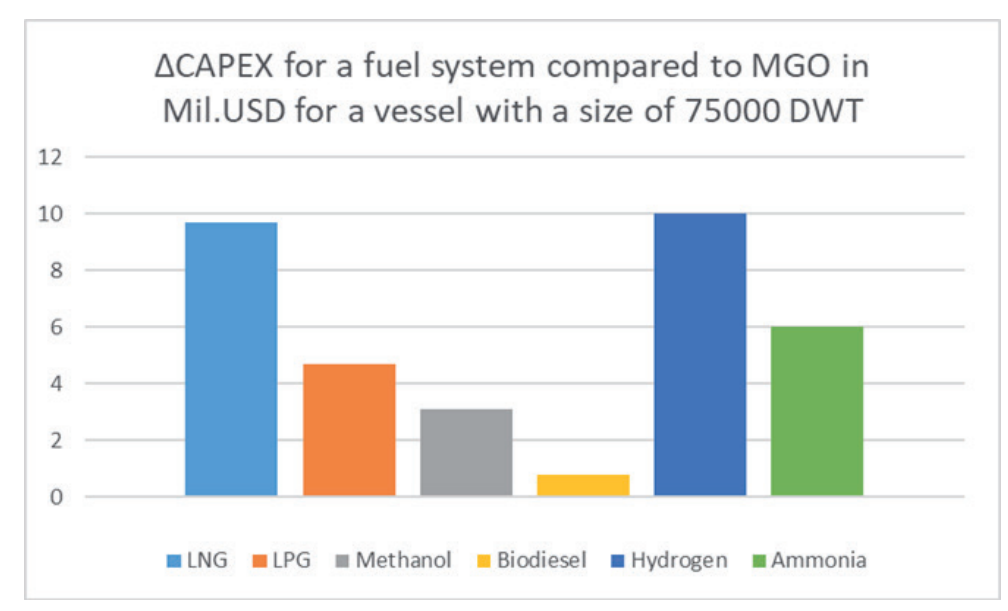

Figure 1. Difference in CAPEX for each fuel system 
The last point which has to be mentioned in the Capital Expenditures (CAPEX) for each fuel system, as shown in Figure 1 above. According to DNV, the differences of CAPEX in a million USD compared to MGO propelled vessels with a size of 75.000 DWT can be seen in the diagram below. As a result, ammonia fuel systems are estimated to be in between the CAPEX of LNG and LPG. Hydrogen is estimated to have a slightly higher CAPEX than LPG fuelled vessels. Biodiesel shows minor changes due to its similar operation compared with MGO. Finally, Methanol also shows advantages in CAPEX due to its similar comparable operation.

\section{Ammonia Inventory Routing Problem of German Ports}

As already mentioned above, the BSR is dominated by short sea shipping operations, mainly handy size ships with an average fuel tank size of 2.000 tons, i.e. due to the $\mathrm{NH}_{3}$ energy density of about $2 / 3$ of MGO, the existing bunker volumes are more than sufficient for shipping in the BSR. An estimation of the infrastructural needs for a BSR wide use of $\mathrm{NH}_{3}$ has besides the local distribution of ammonia terminals, also to consider an inventory routing analysis concerning the fuel supply (Prause \& Prause, 2021). Based on the inventory routing analysis of LNG in German ports, this study hereby displays the implications of the use of ammonia as a marine fuel.

The present research shows that the conversion of LNG storage tanks and the technology corresponding to Ammonia storage technology seems to be possible since the materials used for full containment and single-containment LNG tanks are generally compatible with refrigerated ammonia tanks. Based on the ratio of LNG density versus liquid ammonia density, the maximum liquid level allowed for ammonia storage is expected to be approximately two-thirds of the original design; hence the nominal tank capacity when used for ammonia will be approximately two-thirds of the original design (Black \& Veatch, 2020).

Coming back to the inventory routing analysis of ammonia supply of German ports, the preceding research was based on three different LNG distribution models for the selected German ports, namely the distribution based on delivery via a vessel (model A), the distribution by truck (model B) and finally a combined distribution model based on a multi-model distribution by vessel and truck (model C). All considered models started from the assumption that the central LNG terminal is situated in the port of Brunsbüttel (DE), which is located at the Western end of the Kiel Canal. The same assumption can be made for the ammonia study because the only existing German maritime ammonia terminal is also located in Brunsbüttel and is expected to be further developed. Hence, the underlying routing graphs for LNG are the same as for $\mathrm{NH}_{3}$. However, the energy and density equivalents of $\mathrm{LNG}$ and $\mathrm{NH}_{3}$ differ significantly, i.e. highlighting the fact that one ton of $\mathrm{LNG}$ equals 2.688 tons of $\mathrm{NH}_{3}$, it is, therefore, possible to transform the demand tons of LNG into tons of $\mathrm{NH}_{3}$ and vice versa. Consequently, the daily estimated LNG demand in German ports will increase from 342 tons of LNG to 2.146 tons of $\mathrm{NH}_{3}$, meaning that ports need to upscale their facilities, and due to an increase of $\mathrm{NH}_{3}$ - enhance transport capacity, respectively, which, in turn, brings additional logistics costs.

By applying these findings to the same logistical frame conditions, like in the LNG case, it shows that the size of the $\mathrm{NH}_{3}$ supply vessel in model A has to be enlarged to $8.000 \mathrm{~m}^{3}$ or $6.500 \mathrm{DWT}$ and that one call of all German ports requires a 4-day round trip. Furthermore, it turns out that the total need for $\mathrm{NH}_{3}$ storage in all ports will result in 8.505 tons, of which 4.826 tons have to be allocated to the North Sea German ports. This accounts for the total annual $\mathrm{NH}_{3}$ supply costs of about 1.420 million EUR, where more than 99 per cent of the costs are driven by storage costs in the ports. Compared to the LNG supply case, these costs are more than double as high for the $\mathrm{NH}_{3}$ inventory routing model as for the LNG case.

With the same investigations, it is possible to analyse the costs for the truck distribution (model B) as well as a combined distribution (model $\mathrm{C}$ ) of $\mathrm{NH}_{3}$. Respectively, the results again lead to a higher annual cost level of about 7.20 million EUR that is again significantly higher than in the LNG case, namely about 2.6 times higher. Summing up these insights, it has to be stated that the comparison of LNG and $\mathrm{NH}_{3}$ as marine fuel in the case of German ports generates significantly higher costs for the fuel supply by using ship, truck or a combination of both.

\section{Discussion}

Ammonia shows great potential to become a zero-carbon fuel, playing a role in the future's energy mix. The storage technology for LNG can also be used with modification for $\mathrm{NH}_{3}$, i.e. the handling and storage of $\mathrm{NH}_{3}$ bears an advantage compared to the handling and storage of hydrogen as the other zero- 
carbon fuels. Furthermore, the already good developed infrastructure on the shore side needs fewer investments for the necessary bunker infrastructure. The statutory frame conditions still have to be adopted. On the one hand, the utilisation of ammonia will be driven by shipping industry demand, which is connected with the fuel price that will decrease once production rates increase. On the other hand, in the beginning, the price for green ammonia will be too high, and subsidies have to fix potential market distortion.

By focusing on the physical properties of ammonia, it has to be stated that ammonia only shows roughly half of its potential energy when compared with $\mathrm{MGO}$; since ammonia only enjoys $1 / 3$ of the energy density compared to MGO, and much more, compared to LNG, the energy density is still half as high. Thus, an $\mathrm{NH}_{3}$ propelled vessel would suffer under massive cargo capacity losses due to larger $\mathrm{NH}_{3}$ fuel tanks and thus generate significant opportunity costs. Already in the case of LNG, the issue of lost cargo space spurred intensive discussions in the shipping industry, especially in the context of cargo vessels retrofitting to $\mathrm{LNG}$, followed by generation of GHG emissions due to emission of carbon and methane as unburned residues, also known under methane slip. Nevertheless, ammonia can be used as a marine fuel in combustion engines as well as in fuel cells. It can be assumed that after the adoption by the marine industry, in the beginning, combustion engines will take over the major share of used ammonia, whereas fuel cells will take an increasing share in the upcoming years. The toxicity of ammonia cannot be neglected, but with safe constructions and handling conditions, the anticipated challenges can be solved (Andersson et al., 2020). Thus, the growing interest in ammonia as a marine fuel will accelerate growing ammonia production and the industry moving towards larger production volumes with a growing share of hybrid and later green ammonia to prevent a rivalry between ammonia customers.

The study of the required $\mathrm{NH}_{3}$ supply infrastructure as a marine fuel in the form of an inventory routing analysis reveals significant higher costs than in the case of LNG. The case study of the German ports highlights that larger storage facilities will be needed on the shore and that the stock for the transport infrastructure, no matter in which form -trucks or supply vessels - has to be significantly increased for the $\mathrm{NH}_{3}$ transportation between ports. Hence, the cost for $\mathrm{NH}_{3}$ supply infrastructure for the German ports is double as high as in the LNG case. Consequently, the comparison of LNG against ammonia as a marine fuel, including the supply infrastructure, does not show a clear picture for strategic decisions for the moment.

The consideration of the ammonia storage technologies shows easier storage conditions than hydrogen by requiring smaller tanks with less insulation and necessary equipment for cooling, compressing and reliquefication. Hence, this more straightforward fuel system could lead to a good performance. However, ammonia will not be the only fuel that can achieve a GHG reduction. Methanol, biodiesel and hydrogen will also play a vital role in the energy mix for the shipping industry. In addition, LNG and LPG will also be on the following decades' agenda in terms of transition in maritime shipping and industry.

By virtue of this study, the BSR as a role model in the implementation of cleaner maritime shipping technologies as well as in the face of compliance with the SECA and NECA regulations, thus taking the vanguard flagship position in Europe should make a feasible step forward and become a testbed for ammonia as a marine fuel with a strong first-mover competitive advantage. As a result of burgeoning challenges of the future, in particular related to adverse impacts of climate change and growing challenges associated with maritime shipping and maritime industry pursuant to the entire ecosystem - environmental damage, human health, biodiversity loss, power (digital) concentration and social inequality rise - as shown in the Global Risks Report 2021, underpinned by the ambitious goals of the European Green Deal (2019) and Sustain-able and Smart Mobility Strategy of the European Commission (2020), a call for sustainable mobility and a shift to zero-emission applications in maritime shipping and industry becomes a real short-term problem.

\section{Conclusion}

Ammonia shows great potential to become a zero-carbon fuel, which might play a role in the future's energy mix. Especially in shipping, easy handling and storage conditions can provide an advantage compared to handling and storage of hydrogen as another zero-carbon fuel. Furthermore, already partly developed infrastructure on the shore side leads to fewer investments for the necessary bunker structure than hydrogen. Nevertheless, the $\mathrm{NH}_{3}$ supply and distribution in ports are related to high costs due to storage facilities at ports as well as higher infrastructural costs for transport means.

The study shows that ammonia represents an auspicious alternative fuel for shipping and, due to the special situation in the BSR, can play the role of a perfect lab for testing the properties of ammonia. 
Yet, the fuel price for ammonia and the final share of the energy mix will determine the final utilisation potential. Ammonia shows good advantages in handling and storage, and it ensures long sea voyages without any significant loss of cargo space for a reasonable price. Otherwise, the technology for ammonia propelled vessels are still under construction, and the ammonia supply chains, including the necessary infrastructure for production, distribution, and operations is still underdeveloped. Like all other marine fuels, respective advantages and disadvantages must be considered for each case. The utilisation in deepsea shipping for merchant's vessels might be easier than the utilisation in a cruise ship considering the safety. The scalability of ammonia also shows an obstacle that the industry needs to avoid.

In order to provide feasible solutions in the mid-term and long run, there is an essential need to open up for transitional technologies, such as ammonia now, in order to pave the way for the transition towards e-ammonia or green ammonia, which, in turn, will also secure a smooth turn towards hydrogen and other zero-carbon fuel economies. Therefore, ammonia and its applications in real life might serve as paragons and amplify future environmental transition in the BSR by building upon tested and feasible applications in the frame of a series of national, EU or international projects, bearing in mind the 2030 Climate Target Plan. Currently, ambitious goals of zero-future maritime transportation and mobility bear a clear conundrum, without any specific projection, qualification and quantification of the set goals of the European Green Deal. Thus, specific small actions are needed in order to enable transition itself.

\section{Acknowledgements}

This research article has been supported by the European Regional Development Fund (INTERREG VA South Baltic and INTERREG VB Baltic Sea Region programmes) within the projects "EnviSuM", "GoLNG", "Connect2SmallPorts" and "CSHIPP".

\section{References}

1. Ahlgren, J. (2019) Circular Baltic 2030. Circular Economy in the Baltic Sea Region and Beyond; Global Utmaning: Stockholm, Sweden.

2. Al-Aboosi, F. Y., El-Halwagi, M. M., Moore, M., \& Nielsen, R. B. (2021) Renewable ammonia as an alternative fuel for the shipping industry. Current Opinion in Chemical Engineering, 31, 100670.

3. Al-Douri, A., Alsuhaibani, A. S., Moore, M., Nielsen, R. B., El-Baz, A. A., \& El-Halwagi, M. M. (2021) Greenhouse gases emissions in liquified natural gas as a marine fuel: Life cycle analysis and reduction potential. The Canadian Journal of Chemical Engineering.

4. Al-Enazi, A., Okonkwo, E. C., Bicer, Y., \& Al-Ansari, T. (2021) A review of cleaner alternative fuels for maritime transportation. Energy Reports, 7, 1962-1985.

5. Altrichter, H., Feldman, A., Posch, P.; Somekh, B. (2008) Teachers investigate their work; An introduction to action research across the professions. Routledge, 2nd ed., p. 147.

6. Ampah, J. D., Yusuf, A. A., Afrane, S., Jin, C., \& Liu, H. (2021) Reviewing two decades of cleaner alternative marine fuels: Towards IMO's decarbonization of the maritime transport sector. Journal of Cleaner Production, 128871.

7. Andersson, K., Brynolf, S., Hansson, J., \& Grahn, M. (2020) Criteria and decision support for a sustainable choice of alternative marine fuels. Sustainability, 12(9), 3623.

8. Bach, H., Mäkitie, T., Hansen, T., \& Steen, M. (2021) Blending new and old in sustainability transitions: Technological alignment between fossil fuels and biofuels in Norwegian coastal shipping. Energy Research \& Social Science, 74, 101957.

9. Balcombe, P., Brierley, J., Lewis, C., Skatvedt, L., Speirs, J., Hawkes, A., \& Staffell, I. (2019) How to decarbonise international shipping: Options for fuels, technologies and policies. Energy conversion and management, 182, 72-88.

10. Ben Brahim, T., Wiese, F., \& Münster, M. (2019) Pathways to climate-neutral shipping: A Danish case study. Energy, 188, 116009.

11. Bengtsson, S., Andersson, K., \& Fridell, E. (2011) A comparative life cycle assessment of marine fuels: liquefied natural gas and three other fossil fuels. Proceedings of the Institution of Mechanical Engineers, Part M: Journal of Engineering for the Maritime Environment, 225(2), 97-110.

12. Beyersdorff, S.; Lanthen. (2018) E. Baltic 2030: Bumps on the Road. How the Baltic Sea States are performing on the SDGs; Nordic Council of Ministers and Council of the Baltic Sea States: Copenhagen, Denmark.

13. Bilgili, L. (2021) Comparative assessment of alternative marine fuels in life cycle perspective. Renewable and Sustainable Energy Reviews, 144, 110985.

14. Black \& Veatch (2020) Hybrid LNG \& Ammonia Infrastructure: Key to a Green Economy. 
15. Böhme, K.; Zillmer, S.; Hans, S.; Antikainen, J.; Pyykkonen, S. (2016) Looking Towards 2030: Preparing the Baltic Sea Region for the Future. Full Report; European Commission: Brussels, Belgium.

16. Carvalho, F., Portugal-Pereira, J., Junginger, M., \& Szklo, A. (2021) Biofuels for Maritime Transportation: A Spatial, Techno-Economic, and Logistic Analysis in Brazil, Europe, South Africa, and the USA. Energies, 14(16), 4980.

17. Cheliotis, M., Boulougouris, E., Trivyza, N. L., Theotokatos, G., Livanos, G., Mantalos, G., \& Venetsanos, A. (2021) Review on the safe use of ammonia fuel cells in the maritime industry. Energies, 14(11), 3023.

18. DNV-GL (2020). Ammonia as Marine Fuel, White Paper 2020, Norway.

19. Erdemir, D., \& Dincer, I. (2021) A perspective on the use of ammonia as a clean fuel: Challenges and solutions. International Journal of Energy Research, 45(4), 4827-4834.

20. Erisman, J. W., Otjes, R., Hensen, A., Jongejan, P., van den Bulk, P., Khlystov, A., ... \& Slanina, S. (2001) Instrument development and application in studies and monitoring of ambient ammonia. Atmospheric Environment, 35(11), 1913-1922.

21. Gerlitz, L.; Philipp, R.; Beifert, A. (2018) Smart and Sustainable Cross-Sectoral Stakeholder Integration into Macro-Regional LNG Value Chain. Springer Lecture Notes in Networks and Systems 36, 112-126, DOI: 10.1007/978-3-319-74454-4_11.

22. Giddey, S., Badwal, S. P. S., Munnings, C., \& Dolan, M. (2017) Ammonia as a renewable energy transportation media. ACS Sustainable Chemistry \& Engineering, 5(11), 10231-10239.

23. Gu, Y., \& Wallace, S. W. (2017) Scrubber: A potentially overestimated compliance method for the Emission Control Areas: The importance of involving a ship's sailing pattern in the evaluation. Transportation Research Part D: Transport and Environment, 55, 51-66.

24. Hansson, J., Brynolf, S., Fridell, E., \& Lehtveer, M. (2020) The potential role of ammonia as marine fuel-Based on energy systems modelling and multi-criteria decision analysis. Sustainability, 12(8), 3265 .

25. Haskell, C. (2021) Decarbonising shipping - could ammonia be the fuel of the future? Lloyd's Register, retrieved at https://www.lr.org/en/insights/articles/decarbonising-shipping-ammonia/ on $10^{\text {th }}$ September 2021.

26. Johansson L. \& Jalkanen J. P. (2016) Emissions from Baltic Sea shipping in 2015, Baltic Sea Environment Fact Sheet 2015, HELCOM, Helsinki.

27. Kim, K.; Roh, G.; Kim, W.; Chun, K. (2020) A Preliminary Study on an Alternative Ship Propulsion System Fuelled by Ammonia: Environmental and Economic Assessments. Journal of Marine Science Engineering, 8, 183; doi:10.3390/jmse8030183.

28. Klerke, A., Christensen, C. H., Nørskov, J. K., \& Vegge, T. (2008) Ammonia for hydrogen storage: challenges and opportunities. Journal of Materials Chemistry, 18(20), 2304-2310.

29. Korberg, A. D., Brynolf, S., Grahn, M., \& Skov, I. R. (2021) Techno-economic assessment of advanced fuels and propulsion systems in future fossil-free ships. Renewable and Sustainable Energy Reviews, 142, 110861.

30. Kurien, C., \& Mittal, M. (2022) Review on the production and utilization of green ammonia as an alternate fuel in dual-fuel compression ignition engines. Energy Conversion and Management, 251, 114990.

31. Lloyd's Register. (2020) UMAS Techno-Economic Assessment of Zero-Carbon Fuels; Lloyds Register: London, UK.

32. MacFarlane, D. R., Cherepanov, P. V., Choi, J., Suryanto, B. H., Hodgetts, R. Y., Bakker, J. M., ... \& Simonov, A. N. (2020) A roadmap to the ammonia economy. Joule, 4(6), 1186-1205.

33. Mildenstrey, E. (2021) Ammonia as fuel for the shipping industry, Master Thesis, Wismar University of Applied Sciences, Wismar, Germany.

34. Olaniyi, E. O. Gerlitz, L (2019) LNG Maritime energy contracting model. Journal of Entrepreneurship and Sustainability Issues, 7(1), 574-594.10.9770/jesi.2019.7.1(40).

35. Olaniyi, E. O; Prause, G (2020) A Comparative Study on SECA Compliance Options for Maritime Fuel Producers. Journal of Entrepreneurship and Innovation in Emerging Economies. DOI: $10.1177 / 2393957519885521$.

36. Palys, M. J., Wang, H., Zhang, Q., \& Daoutidis, P. (2021) Renewable ammonia for sustainable energy and agriculture: vision and systems engineering opportunities. Current Opinion in Chemical Engineering, 31, 100667.

37. Prause, F; Prause, G. (2021) Inventory Routing Analysis for Maritime LNG Supply of German Ports, Transport and Telecommunication Journal, 22(1), 67-86. DOI: 10.2478/ttj-2021-0006. 
38. Prause, G.; Olaniyi, E. O. (2019) A compliance cost analysis of the seca regulation in the Baltic Sea. Journal of Entrepreneurship and Sustainability Issues, 6(4), 1907-1921. DOI: 10.9770/jesi.2019.6.4(26).

39. Prussi, M., Scarlat, N., Acciaro, M., \& Kosmas, V. (2021) Potential and limiting factors in the use of alternative fuels in the European maritime sector. Journal of Cleaner Production, 291, 125849.

40. Rehbein, M. C., Meier, C., Eilts, P., \& Scholl, S. (2019) Mixtures of ammonia and organic solvents as alternative fuel for internal combustion engines. Energy \& Fuels, 33(10), 10331-10342.

41. Reiter, A. J., \& Kong, S. C. (2008) Demonstration of compression-ignition engine combustion using ammonia in reducing greenhouse gas emissions. Energy \& Fuels, 22(5), 2963-2971.

42. Sánchez, A., Castellano, E., Martín, M., \& Vega, P. (2021) Evaluating ammonia as green fuel for power generation: A thermo-chemical perspective. Applied Energy, 293, 116956.

43. Seo, S., Chu, B., Noh, Y., Jang, W., Lee, S., Seo, Y., \& Chang, D. (2016) An economic evaluation of operating expenditures for LNG fuel gas supply systems onboard ocean-going ships considering availability. Ships and Offshore Structures, 11(2), 213-223.

44. Stalmokaite, I., \& Yliskylä-Peuralahti, J. (2019) Sustainability transitions in Baltic Sea shipping: exploring the responses of firms to regulatory changes. Sustainability, 11(7), 1916.

45. Sys, C., Vanelslander, T., Adriaenssens, M., \& Van Rillaer, I. (2016) International emission regulation in sea transport: Economic feasibility and impact. Transportation Research Part D: Transport and Environment, 45, 139-151.

46. Topsoe (2020) Ammonia - an industrial view of ammonia as a marine fuel; Alfa Laval, Hafnia, Haldor Topsoe, Vestas, and Siemens Gamesa; Denmark.

47. Valera-Medina, A., Amer-Hatem, F., Azad, A. K., Dedoussi, I. C., De Joannon, M., Fernandes, R. X., .. \& Costa, M. (2021) Review on ammonia as a potential fuel: from synthesis to economics. Energy \& Fuels, 35(9), 6964-7029.

48. Valera-Medina, A., Pugh, D. G., Marsh, P., Bulat, G., \& Bowen, P. (2017) Preliminary study on lean premixed combustion of ammonia-hydrogen for swirling gas turbine combustors. International Journal of Hydrogen Energy, 42(38), 24495-24503.

49. van Aardenne, J., Colette, A., Degraeuwe, B., Hammingh, P., Viana, M., and Vlieger, I. (2013) The impact of international shipping on European air quality and climate forcing, Technical Report No. 4/2013, EEA (European Environment Agency), Copenhagen, Denmark, 1-84, 2013.

50. Vedachalam, S., Baquerizo, N., \& Dalai, A. K. (2022) Review on impacts of low sulfur regulations on marine fuels and compliance options. Fuel, 310, 122243.

51. Wan, Z., Tao, Y., Shao, J., Zhang, Y., \& You, H. (2021) Ammonia as an effective hydrogen carrier and a clean fuel for solid oxide fuel cells. Energy Conversion and Management, 228, 113729.

52. Xing, H., Spence, S., \& Chen, H. (2020) A comprehensive review on countermeasures for $\mathrm{CO}_{2}$ emissions from ships. Renewable and Sustainable Energy Reviews, 134, 11022.

53. Zamfirescu, C., \& Dincer, I. (2008) Using ammonia as a sustainable fuel. Journal of Power Sources, 185(1), 459-465.

54. Zis, T. P., \& Cullinane, K. (2020) The desulphurisation of shipping: Past, present and the future under a global cap. Transportation Research Part D: Transport and Environment, 82, 102316. 